\title{
¿MATANDO A LA GALLINA DE LOS HUEVOS DE ORO?: ALGUNOS APUNTES SOBRE LA NUEVA REGULACIÓN DE LAS VIVIENDAS DE USO TURÍSTICO (ESPECIAL REFERENCIA AL CASO ANDALUZ)
}

\author{
MARÍA LUISA ROCA FERNÁNDEZ-CASTANYS \\ Profesora Titular de Derecho Administrativo. \\ Universidad de Almería ${ }^{1}$
}

\begin{abstract}
Resumen
En el presente artículo se realiza una aproximación a la problemática que plantea la reciente regulación de las viviendas de uso turístico, con especial referencia a la normativa andaluza. Se inicia con una breve referencia a la llamada economía colaborativa y las plataformas P2P para seguir con un análisis de la evolución histórica de la normativa turística en la que se inserta la regulación de las viviendas de uso turístico hasta su regulación actual, con especial referencia a los recientes pronunciamientos jurisprudenciales al respecto.

Palabras clave: Viviendas de uso turístico. Economía colaborativa. Plataformas P2P. Normativa turística. Regulación de las viviendas de uso turístico en Andalucía.

\section{Abstract}

The aim of this paper is to deal with the problems that the recent regulation of the private houses for tourist uses implies. Thus, starts with a brief reference to the socalled ?collaborative consumption? and P2P platforms, to be focused on the problems of the current regulation of this question in Andalucía. In addition, considers the latest jurisprudence in this regard.
\end{abstract}

Keywords: Home sharing platforms. Collaborative consumption. P2P. Tourism regulation. Home sharing in Andalucía.

\section{INTRODUCCIÓN}

Durante los últimos tiempos ha emergido con fuerza una -aparente- nueva modalidad alojativa que ha suscitado un interesante debate jurídico. Como en otras tantas ocasiones, la rápida evolución de la sociedad ha sorprendido al legislador, que no ha previsto la regulación de un fenómeno impulsado por el imbatible ascenso de las nuevas tecnologías: las posibilidades que éstas ofrecen son infinitas, y la actividad turística en general y, en particular, la de alojamiento, dan buena muestra de ello.

\footnotetext{
${ }^{1}$ mlroca@ual.es
} 
En este contexto se sitúa la popularización del alojamiento en las llamadas «viviendas turísticas» (o «viviendas vacacionales», «de», «para uso»o «fin» turístico» ${ }^{2}$ ) que, en realidad, no son nada nuevo, ya que su configuración se remonta, como veremos, a las primeras normas turísticas. La verdadera novedad reside en el medio por el que se organiza su comercialización: a través del uso de las TIC's (las conocidas, en inglés como plataformas «peer to peer»-de igual a igual- o por sus siglas $P 2 P^{3}$ ), lo que supone una universalización de la oferta con un notable ahorro de costes de transacción (al suprimirse los intermediarios ${ }^{4}$ ), así como un aumento de la confianza de los usuarios mediante la instauración de medios de información, confirmación, reserva y pago rápidos y seguros.

Ello ha conducido a su veloz crecimiento ${ }^{5}$, causando así notable alarma en los empresarios hoteleros, por cuanto han visto como se ha producido un significativo desplazamiento de la demanda a esta nueva fórmula ${ }^{6}$, con las consiguientes pérdidas económicas para el sector hotelero. Sus presiones-y la de la misma sociedad, al ser los

\footnotetext{
${ }^{2}$ La denominación varía según la Comunidad Autónoma de que se trate: así en Andalucía se habla de viviendas «con fines turísticos», mientras que en Castilla y León y Cataluña la denominación es la de viviendas «de uso turístico» y en Euskadi de «viviendas para uso turístico».

${ }^{3}$ Como hace notar la la Comisión Nacional de los Mercados y de la Competencia (CNMC), en su Informe económico sobre el Decreto 113/2015, de 22 de mayo, por el que se aprueba el Reglamento de las viviendas vacacionales de la Comunidad Autónoma de Canarias- LA/03/15, pág. 2, lo característico de estas plataformas («de iguales») es que el mismo agente puede actuar en unos casos como demandante y en otros como proveedor de alojamiento.

${ }^{4}$ Sobre la intermediación turística vid. PÉREZ GUERRA, R., "La regulación jurídico-administrativa de la intermediación turística en España a la luz de la nueva Directiva de Viajes Combinados", RArAP núm. 49-50 (2017), págs. 422-453.

5 Como afirma la CNMC: «La razón fundamental por la que estas plataformas han sido exitosas es porque han conseguido solucionar los problemas que tradicionalmente habían impedido la realización de estas transacciones. En primer lugar, han reducido los costes de transacción entre oferta y demanda, lo que facilita la entrada y permite ampliar el tamaño del mercado. En concreto se caracterizan por aprovechar tanto las ventajas de las tecnologías de la información -en particular Internet- como el desarrollo de métodos electrónicos de pago seguros, par de este modo poner en contacto a los oferentes y demandantes. La entrada de nuevos oferentes ha sido muy intensa en todos los mercados donde están presentes estas plataformas (...). En segundo lugar, han creado mecanismos de generación de reputación y confianza que resuelven los problemas de información típicos en estos mercados. Mediante estas plataformas, los usuarios disponen de información sobre el bien o servicio intercambiado -por ejemplo, el alojamiento en casa de un particular- y cómo ha sido valorado este servicio por otros usuarios. Estos sistemas de recomendación y valoración, solucionan problemas de información, permiten generar reputación y confianza -algo fundamental en el éxito de un mercado peer to peer- y proporcionan incentivos muy poderosos para prestar el servicio de calidad. En tercer lugar, han facilitado que personas individuales compartan determinados costes fijos asociados a las transacciones que realizan en la plataforma, como los de facturación o publicidad, lo que ayuda a reducir considerablemente los costes de entrada. En realidad, han permitido que personas individuales -que carecen de los recursos de las empresas tradicionales- puedan entrar y competir en un mercado».

${ }^{6}$ En el informe correspondiente a enero de 2017, Exceltur confirma que en 2016 se cumplieron los pronósticos sobre los efectos negativos que sobre el sector turístico español y la sostenibilidad de ciertos destinos iba a generar el crecimiento de conversión de viviendas en alojamientos turísticos a través de plataformas $P 2 P$. Según los datos que se recogen en este informe el alojamiento en viviendas de uso turístico en plataformas P2P ha crecido en 2016 en casi un 75\% (74'8 \%) respecto del año anterior (lo que hace un total de 1.763.471 plazas ocupadas en 2016 frente al 1.271.842 de 2015); mientras que las plazas en oferta alojativa reglada (hoteles, apartamentos, camping y casas rurales) creció tan sólo un 1'6 \% en 2016, representando un total de 3.305.428. Estos datos llevan los empresarios hoteleros a exigir «una respuesta estratégica del país que garantice el cumplimiento de unas normativas lo más homogéneas posibles a escala nacional y que sean válidas para asegurar que cada comunidad autónoma y destino establezcan en función de su modelo turístico, sistema de vivienda y de convivencia de la sociedad local». El texto del informe está disponible en:http://www.exceltur.org/wp-content/uploads/2017/01/InformePerspectivas-N59-Balance-del-a\%C3\%B10-2016-y-previsiones-para-2017-web.pdf
} 
vecinos de los inmuebles o el barrio en los que se ubican estas "viviendas" los principales perjudicados- han sido determinantes a la hora de pergeñar su marco jurídico, labor que ha planteado no pocos problemas, que alcanzan a cuestionar la misma conveniencia de esta normativa.

Una de las opiniones más críticas ha sido la de la Comisión Nacional de los Mercados y de la Competencia (CNMC), que se muestra partidaria de eliminar los obstáculos a su implantación, impugnando, como veremos, alguna de las últimas normas autonómicas sobre viviendas turísticas, por -entre otras razones-«limitar la competencia»y «favorecer a los operadores ya establecidos» ${ }^{7}$.

El propósito de este artículo es realizar una primera aproximación a este fenómeno; Para ello, el quid de la cuestión estriba en determinar si debe o no regularse dicha actividad, cómo debe hacerse en su caso (¿hasta qué grado de detalle?) o a quien le corresponde la competencia para ello.

Hasta muy recientemente, uno de los argumentos en contra de su regulación ha sido que dichas viviendas constituyen una manifestación de la llamada «economía colaborativa ${ }^{8}$, economía que, básicamente, consiste en el intercambio espontáneo de bienes y servicios entre individuos de una comunidad virtual $\sin -0$ insignificantecontraprestación económica, basada en la confianza mutua). Así considerada esta actividad de alojamiento turístico, la intervención pública supondría un innecesario encorsetamiento de esta modalidad de la economía colaborativa, así como una intromisión injustificada en una actividad inter privatos. Sin embargo, en contra de este razonamiento puede aducirse que, a día de hoy -y habida cuenta el estado de desarrollo alcanzado por esta actividad "colaborativa"- resulta insostenible mantener que las viviendas turísticas sean una manifestación del turismo colaborativo(al menos, en su acepción primigenia ${ }^{9}$ ), porque existe un indudable e innegable animus lucrandi del propietario y/o explotador, además de la intervención -en muchos casos- de un intermediario que actúa a modo de agencia (casi siempre on line) a cambio de la

\footnotetext{
${ }^{7} \mathrm{La}$ CNMC ofrece en el citado Informe económico una idea cristalina sobre su criterio. En el cuarto párrafo de su primera página puede leerse que «La entrada de las viviendas vacacionales está dinamizando el mercado de alojamiento turístico (...) de forma extraordinaria, incrementando el nivel de presión competitiva, reduciendo los precios, proporcionando incentivos para una mayor calidad y eficiencia, y aumentándola variedad disponible para los consumidores. Al obstaculizar de forma sustancial la entrada de este operador y limitar su capacidad de competir, el Decreto reduce el nivel de competencia que enfrentan los operadores establecidos -fundamentalmente hoteles y apartamentos turísticos- y evita que los efectos positivos de una mayor competencia - en términos de precios, calidad, variedad e innovación- se trasladen al conjunto de la sociedad, reduciendo el bienestar general».

${ }^{8}$ La incidencia de la economía colaborativa en el turismo se manifiesta principalmente en materia de alojamiento y del transporte. En relación con este último vid. LEIÑENA MENDIZÁBAL, E., «Los nuevos sistemas de utilización compartida de vehículos de transporte («carpooling» y «carsharing»): entre la economía colaborativa y la competencia desleal», Revista de Derecho mercantil núm. 296 (2015), pág. 296.

Como destaca la CNMC en ese Informe económico, la razón fundamental por la que las plataformas peer to peer han sido exitosas es «porque han conseguido solucionar los problemas que tradicionalmente habían impedido la realización de muchas de estas transacciones. En primer lugar, han reducido los costes de transacción entre oferta y demanda, lo que facilita la entrada y permite ampliar el tamaño del mercado. En concreto, se caracterizan por aprovechar tanto las tecnologías de información -en particular Internetcomo el desarrollo de métodos electrónicos de pago seguros, para de este modo poner en contacto a los oferentes y demandantes».

${ }^{9}$ Fórmula que se limitaría a tipos de actividad como el couchsourfing (acoger viajeros en el sofá de casa) o el homeexchange (o intercambio de casas completas). En este sentido vid. GUILLÉN NAVARRO, N.A., «La vivienda de uso turístico y su incidencia en el panorama normativo español», RArAP núm. 4546 (2015), pág. 103.
} 
correspondiente comisión. Es decir, con este tipo de alojamiento turístico se pretende la causa de este contrato ${ }^{10}$ - rentabilizar una vivienda (o parte de ella, en su caso) ofreciendo su uso temporal a cambio de un precio; de este modo, el encuadre «colaborativo» resulta completamente desbordado, transmutándose la idea original en un verdadero negocio que mueve millones de turistas ${ }^{11}$ que, consecuentemente, demandan unas garantías mínimas que justifican la intervención y el control administrativo.

Sentada la necesidad de su regulación, procede dilucidar si esta actividad de alojamiento puede englobarse bajo alguna de las figuras jurídicas ya conocidas o si, por el contrario, se trata de un fenómeno singular que requiere una normativa específica; además es preciso saber -de estimarse oportuna tal regulación especial- cuál debe ser su grado de detalle, determinando hasta qué extremo debe llegar la intervención administrativa para que el -real o aparente- celo en la protección de los usuarios no termine por asfixiar o atrofiar esta "exitosa fórmula", expulsando a estos nuevos operadores del mercado (o desalentando a los nuevos) al obligarlos a ajustarse a fórmulas y parámetros demasiado estrictos, habituales y/o de sobra conocidos (detallada relación de equipamientos y servicios, inscripción en Registros administrativos, placas exteriores de identificación...); porque precisamente en la omisión de estas obligaciones administrativas reside la novedad, la diferenciación, la frescura y, sin duda, gran parte del éxito de estas viviendas turísticas entre los usuarios, que, por cierto, pueden resultar finalmente perjudicados por una regulación "protectora" demasiado exigente.

\footnotetext{
${ }^{10}$ La STS de 19 de noviembre de 1990, sintetiza la doctrina del Alto Tribunal en torno la polémica cuestión de la causa de los contratos: «a) Que partiendo de las directrices doctrinales y judiciales respecto al concepto de causa de los contratos e, incluso, la conexión entre la misma y los motivos, se puede verificar esta síntesis jurisprudencial: Como es sabido, a través del artículo 1274 del Cc se da un supuesto de inexistencia contractual — por falta de causa STS 24 de febrero de 1986- y que tal carencia proviene en razón al sentido de la causa inmerso en el artículo 1275 del Cc sobre lo que ha de advertirse, en línea de principio, que para entender el verdadero alcance o significado de la causa como razón de ser del contrato $-\mathrm{y}$ con una incesante polémica doctrinal respecto a su exacta configuración-, no puede omitirse el peso que en toda esa configuración debe ostentar la real intención o explicación del componente de voluntad que cada parte proyecta al consentir el negocio, y que si ésta puede explicitarse, en el conjunto de las circunstancias que emergen de la situación subyacente que origina el negocio que se lleva a cabo, ha de tenerse en cuenta la misma para integrar aquel concepto, pues de esa forma se consigue localizar un presupuesto de razonabilidad que funda el intercambio de prestaciones efectuado; bien es cierto que con ello se margina la dualidad entre la causa como elemento objetivo trascendente, con los móviles internos de cada interesado — es conocida esa distinción, expuesta entre otras muchas en la STS 30 de diciembre de 1985 de que «la causa se diferencia de los motivos en que se determina por los móviles con trascendencia jurídica, que incorporados a la declaración de voluntad en forma de condición o modo forman parte de aquélla a manera de motivo esencial impulsivo o determinante-; mas se repite, según la información que late en ese principio jurisprudencial, la conjunción entre ambos es posible, sobre todo, si al ser lícitos los móviles particulares que implícitamente explican el negocio en su respectiva repercusión interna para cada interesado, coadyuvan al hallazgo de aquel designio de razonabilidad, e, incluso, partiendo de la triple distinción de la doctrina más decantada, entre la causa de la atribución, causa de la obligación y causa del contrato (por qué el tributario está jurídicamente facultado para recibir el desplazamiento patrimonial, fuente constitutiva de la obligación, o fin común perseguido en el negocio por las partes, respectivamente) habría de adscribir ese juego de conjunción en el primer expediente de ese proceso, esto es, en la causa de la atribución».

${ }^{11}$ Como señala el Preámbulo del Decreto andaluz 28/2016, de 2 de febrero, de las viviendas con fines turísticos y de modificación del Decreto 194/2010, de 20 de abril, de establecimientos de apartamentos turísticos: «Este aumento se vincula a las nuevas formas de viajar, el deseo de las personas turísticas de tener una relación más directa con las personas residentes del destino que eligen, la irrupción de las nuevas y rápidas formas de comercialización, directas y sin intermediarios, en especial, numerosos portales de Internet».
} 
Las reflexiones anteriores permiten iniciar el estudio del régimen jurídico de las viviendas de uso turístico, afirmando que su "atención normativa" está plenamente justificada. Ahora bien, siendo esto cierto, no lo es menos que debe buscarse una fórmula ponderada y "justa", por cuanto -como advierte la CNMC-«una regulación innecesaria o desproporcionada perjudicaría a los consumidores y al interés general, además de suponer un obstáculo a la competencia efectiva» ${ }^{12}$.

\section{MARCO JURÍDICO DE LAS VIVIENDAS DE USO TURÍSTICO: EVOLUCIÓN HISTÓRICA Y REGULACIÓN ACTUAL}

Como se ha anticipado, las viviendas turísticas no son algo nuevo, puesto que ya aparecían previstas en la Orden de 17 de enero de 1967, de ordenación de apartamentos, «bungalows»y otros alojamientos similares de carácter turístico ${ }^{13}$. No obstante, dicha norma no establecía una nítida separación entre las distintas modalidades recogidas en ella.

No es hasta quince años después, cuando se aprueba el Real Decreto 2877/1982, de 15 de octubre, de ordenación de apartamentos y viviendas vacacionales, se definen las viviendas turísticas vacacionales por contraposición a los apartamentos como «unidades aisladas de apartamentos, bungalows, villas y chalets similares y, en general, cualquier vivienda que con independencia sus condiciones de mobiliario, equipo, instalaciones y servicios, se ofrezcan en régimen de alquiler por motivos vacacionales o turísticos». Aparte de dicha definición, poco más aportaba esta norma como no sea la previsión de la necesaria notificación a la Administración de la dedicación turística de la vivienda como paso previo a su apertura y funcionamiento, con el fin de terminar con las actividades clandestinas.

Su parquedad se justifica si se tiene en cuenta que su aprobación se produce tras la entrada en vigor de la Constitución española que reconoce la competencia exclusiva de las CCAA en materia de turismo. Se trataba, en definitiva, de una norma dictada al amparo de la cláusula residual del artículo 149.3 de la CE y mediante la que se trataba de dotar una norma de contenido básico y aplicación subsidiaria ${ }^{14}$ en tanto germinara la

\footnotetext{
12 En este sentido la CNMC sugiere en su Informe económico la eliminación de «cualquier tipo de moratoria en la autorización de nuevas viviendas turísticas, suprimiendo su inscripción y eliminando requisitos de estancias».

${ }^{13} \mathrm{Su}$ Preámbulo justifica dicha regulación en el notable desarrollo experimentado por tales modalidades de alojamiento extra hotelero «a los que es ya obligado dotar de una normativa que encauce la actividad que en ellos se realiza (...) teniendo en cuenta las peculiaridades de esta especial modalidad de alojamiento y dándole el adecuado y flexible tratamiento que exigen tanto la fisonomía de la clientela como el régimen empresarial en que la actividad se manifiesta», diferente de la prevista para los arrendamientos de vivienda amueblada, de los que se diferencian con claridad «por cuanto en este último caso se trata de la transferencia del uso temporal y oneroso de una vivienda, sin que el arrendador se obligue a prestar ningún servicio ni a realizar actividad alguna en beneficio del arrendatario, mientras que en el primero lo característico es el conjunto de asistencias que recibe el cliente de la Empresa desde el momento mismo de la ocupación del alojamiento, no desvirtuando su naturaleza el que se presten todos o solamente algunos de los servicios que en la propia Ordenación se mencionan».

${ }^{14}$ Supletoriedad que fue reconocida jurisprudencialmente (STSJ de Madrid 444/2013, de 7 de mayo, rec. 1095/2009): «Ante la total ausencia de regulación de las viviendas turísticas vacacionales en la legislación autonómica, debemos despejar si tal ausencia de regulación constituye una laguna de la legislación autonómica que deba ser integrada con la aplicación supletoria, al amparo del artículo 149.3 C , del citado RD 2877/1982, de 15 de octubre, de Ordenación de Apartamentos Turísticos y de Viviendas Turísticas Vacacionales, dictado por el Estado cuando aún no se habían asumido por la Comunidad de Madrid sus competencias exclusivas en materia de turismo, asunción que se produjo con el
} 
normativa regional; esto es, como se declara en su Preámbulo, con ella se atendía a un fenómeno que era necesario prever «por imperativo de la política económica general», máxime en tanto la normativa estatal previa - la Orden de 1967- había quedado obsoleta y no habían visto la luz la mayoría de las leyes de turismo.

$\mathrm{Al}$ amparo de la competencia exclusiva en materia de turismo prevista en la $\mathrm{CE}$ (artículo 148.1.9) ${ }^{15}$ las Comunidades Autónomas han empezado a aprobar recientemente las primeras normas sobre viviendas vacacionales. El punto de inflexión de este proceso se encuentra en el desgaje en 2013 del régimen común de los arrendamientos de temporada ${ }^{16}$ contemplados en la LAU de aquellas operaciones que tengan por objeto «la cesión temporal de uso de la totalidad de una vivienda amueblada y equipada en condiciones de uso inmediato, comercializada o promocionada en canales de oferta turística y realizada con finalidad lucrativa, cuando esté sometida a un régimen específico derivado de su normativa sectorial» ${ }^{17}$.

Estatuto de Autonomía de 1983, aprobado por LO 3/1983, de 25 de febrero, en forma de competencias legislativas plenas. O bien, si, por el contrario, esta ausencia de regulación se debe a una decisión voluntaria del legislador autonómico que habría querido no regular tales viviendas turísticas vacacionales en el libre ejercicio de sus competencias exclusivas plenas en materia de turismo, supuesto éste en el que dicho Real Decreto debería entenderse desplazado por la Ley autonómica 1/1999, por lo que a las viviendas turísticas vacacionales se refiere, de forma que estas viviendas turísticas vacacionales, en la Comunidad de Madrid, al no ser mencionadas en dicha Ley ni en sus reglamentos de desarrollo, no estarían sometidas a la intervención de la Administración turística autonómica. Pues bien, debemos entender que el citado Real Decreto debe aplicarse de forma supletoria, ex artículo 149.3 CE, porque la propia Comunidad de Madrid así lo ha entendido al considerarlo aplicable con relación a las viviendas turísticas vacacionales, habiéndolo manifestado así de forma expresa y clara como, a continuación, veremos».

${ }^{15}$ Sobre las competencias turísticas de las CCAA, vid., por todos, CEBALLOS MARTÍN, M ${ }^{\mathrm{a}}$ M. y PÉREZ GUERRA, R., «A vueltas con el régimen jurídico-administrativo de la distribución de competencias en materia de turismo y de otros títulos que pueden que inciden directamente sobre el mismo: el ejercicio de competencias turísticas por la Comunidad Autónoma andaluza», RAAP núm. 27 (1996) págs. 95-170.

${ }^{16}$ Modificación operada por la Ley 4/2013, de 4 de junio, de medias de flexibilización y fomento del mercado de alquiler de viviendas.

17 Como señala el TS «constituye constante doctrina legal, que la nota esencial que caracteriza los arrendamiento de temporada, a que se refiere el artículo 2.1 de la LAU de 1964 ; para excluirlos de su normativa especial y quedar sujetos, únicamente, a lo expresamente pactado y a las leyes comunes, es la existencia de un plazo concertado en atención, no a la necesidad permanente que el arrendatario tenga de ocupar la vivienda que le sirva de habitual residencia familiar, o un local donde establecer con carácter permanente un negocio o industria, sino para desarrollar de una manera accidental y en épocas determinadas esas actividades negociales o para habitar transitoriamente y por razones diversas la vivienda; debiendo entenderse el requisito de la "temporalidad" de modo amplio y flexible, cuando claramente se infiere que el uso u ocupación del inmueble responda a exigencias circunstanciales, esporádicas o accidentales determinantes del contrato, y no a la necesidad de habitarlo permanentemente, ya que dicho requisito de temporalidad guarda relación, no con el plazo de duración puramente cronológico, sino con la finalidad a que va encaminado el arrendamiento determinante de acción (SSTS 19 febrero 1982 y 15 diciembre 1999 , entre otras). Constituyen pues elementos configuradores del arrendamiento de temporada: el negativo, de no constituir la residencia habitual del locatario y no tener vocación de permanencia o de satisfacer la necesidad de vivienda del arrendatario; y el positivo, de la limitación temporal u ocasional de los periodos de ocupación, verificados de manera más o menos discontinua y con una mayor o menor frecuencia, pero siempre interrumpidos por la preferencia otorgada al hogar habitual, único que cubre la necesidad permanente de ocupación, frente a las motivaciones de mera conveniencia, comodidad o capricho determinantes del arriendo. La exigencia de que el inmueble se "ocupe" únicamente por una temporada, que establece el citado precepto de la LAU de 1964 , revela que lo importante para definir el contrato no es la duración del arrendamiento o el plazo pactado, sino el periodo real de ocupación del inmueble, cualquiera que sea el espacio más o menos corto del tiempo de utilización, en tanto sea revelador de que la estancia del locatario no es la de su residencia habitual, sino que la finca se ocupa discontinuamente por parte de quien habitualmente disfruta de otra vivienda que 
Y es que, si bien en una primera aproximación, podría pensarse que se trata de una especie o modalidad del arrendamiento de temporada, se diferencia de éste por una serie de notas peculiares (por ejemplo, la prestación de determinados servicios a los usuarios) que aconsejan su regulación independiente con una correlativa y más intensa intervención administrativa ${ }^{18}$ con el fin de evitar «situaciones de intrusismo y competencia desleal que van en contra de los destinos turísticos», evitado actuaciones fraudulentas ${ }^{19}$.

La aprobación de tales normas conduce, como veremos, a un dispar marco normativo según la Comunidad Autónoma de la que se trate. Así, en aquellas CC AA en las que se ha alumbrado esta normativa peculiar será ésta la que se aplique en primer lugar; en cambio, en las CC AA que no hayan hecho uso de esta competencia normativa deberá seguirse aplicando la normativa civil correspondiente. Incluso, en algunos casos se permite que aun, existiendo normativa sectorial, el propietario de la vivienda pueda optar por someter su actividad a esta o la normativa sobre arrendamientos urbanos ${ }^{20}$, si bien, como aclara la STSJ de Madrid 291/2016, de 31 de mayo ${ }^{21}$ : «que dicho régimen sea opcional para los propietarios de viviendas no significa que la regulación sea conforme a Derecho[pues] obviamente, no es la posibilidad de excluir la aplicación de la norma por el destinatario de la misma lo que determina su conformidad o no a Derecho (...), sino su adecuación por si misma a dicho Ordenamiento Jurídico, con independencia de la elección del particular de acometer o no dicha actividad regulada».

\section{ESPECIAL REFERENCIA A LA COMUNIDAD AUTÓNOMA ANDALUZA}

Andalucía ha sido una de las últimas Comunidades Autónomas que se ha provisto de una norma específica ${ }^{22}$. Hace poco más de un año se aprueba el Decreto 28/2016, de 2 de febrero, de viviendas con fines turísticos, y de modificación del

satisface su necesidad permanente, siendo la referencia a la temporada de verano que contiene la expresada norma de carácter meramente ejemplificativo. Obedeciendo la finalidad protectora del inquilino, que reconoce también la vigente LAU de 1994 en favor del arrendamiento de vivienda, y que se excluye ahora para los arrendamientos de uso distinto aun comprendidos en el ámbito de esta legislación especial, a la singular tutela que merece la vivienda destinada efectivamente a residencia habitual del locatario, es clara la justificación de que los inmuebles que no satisfacen esta necesidad esencial y permanente de vivienda no merezcan dicha protección legal».

${ }^{18}$ Sobre la intervención administrativa en materia turística vid. PÉREZ GUERRA, R., «La intervención administrativa en el sector turístico español: la política turística», RArAP núm. 43-44 (2011), págs. 396423.

19 Algunos autores hacen notar que el arrendamiento de temporada se ha utilizado durante años para suplantar la normativa específicamente turística por aquellos propietarios que alojaban huéspedes temporales con una finalidad inequívocamente turística más allá de las cuestiones puramente fiscales (ROMÁN MÁRQUEZ, A., «Las viviendas particulares dedicadas a la actividad de alojamiento turístico. $\mathrm{Su}$ exclusión de la Ley de arrendamientos urbanos», RIDJ núm. 1 (2014), pág. 4; VERDERA IZQUIERDO, B., «El arrendamiento de temporada frente a las estancias turísticas en viviendas», El consultor inmobiliario núm. 107 (2009), págs. 1-17.

${ }^{20}$ Así ocurre en la Comunidad de Madrid (Decreto 79/2014, de 10 de julio, por el que se regulan los apartamentos turísticos y las viviendas de uso turístico.

${ }^{21}$ Proc. núm. 65/2015.

${ }^{22}$ Como señala el primer párrafo de su Preámbulo, este Decreto se dicta al amparo de las competencias exclusivas en materia de turismo que tiene atribuida la Comunidad Andaluza al amparo de lo dispuesto en el artículo 71 de su Estatuto de Autonomía y en el artículo 37.1.14 que considera un principio rector de las políticas públicas de la Comunidad Autónoma el desarrollo del sector turístico como elemento económico estratégico de Andalucía. 
Decreto 194/2010, de 20 de abril, de establecimientos de uso turístico (en adelante, DVFT). De este modo, Andalucía se suma a las Comunidades que disciplinan esta «nueva» modalidad alojativa ${ }^{23}$ al articular un marco jurídico propio y de aplicación preferente para las viviendas con fines turísticos (VFT).

El DVFT contiene una escueta aproximación (su contenido se estructura en 11 artículos) a esta «novedosa «fórmula no exenta de polémica. A continuación, se hará una referencia a las principales cuestiones en él contenidas.

\subsection{Justificación}

El DVFT basa su nacimiento en la necesidad de establecer unas mínimas garantías de calidad y seguridad ${ }^{24}$ (entendida ésta como seguridad física y jurídica) para las personas usuarias turísticas, así como en razones de seguridad pública y de protección del medio ambiente y entorno urbano; Veamos a continuación, de forma breve, cada uno de los argumentos aludidos.

3.1.1. La protección de la calidad y la seguridad de los usuarios y de la seguridad pública

Además de la protección de la calidad y de la seguridad física, se pretende una protección de la seguridad jurídica de las personas como «usuarias de unos servicios específicos», de forma que «el disfrute, por un lado, y la tranquilidad, por otro, puedan ser garantizados»; esta garantía se realiza mediante «la exigencia de una serie de requisitos que se consideran mínimos ${ }^{25}$ para lograr el confort y la seguridad necesaria».

\footnotetext{
${ }^{23}$ Además de Andalucía, disponen de regulación específica al respecto: Asturias, Decreto 48/2016, de 10 de agosto, de Viviendas vacacionales y viviendas de uso turístico de Asturias (BOPA núm. 191, de 17 de agosto); Aragón, Decreto 80/2015, de 5 de mayo, del Gobierno de Aragón, por el que aprueba el Reglamento de las viviendas de uso turístico en Aragón (BOA núm. 90, de 14 de mayo); Baleares, arts. 50 y ss. de la Ley 8/2012, de 19 de julio, de Turismo de Illes Balears (BOIB núm. 106, de 21 de julio); Castilla y León, Decreto 3/2017, de 16 de febrero, que regula los establecimientos de alojamiento en la modalidad de vivienda de uso turístico en la Comunidad de Castilla y León (BOCL núm. 33, de 17 de febrero); Cataluña, Decreto 159/2012, de 20 de noviembre, de establecimientos de alojamiento turístico y de viviendas de uso turístico de Cataluña (DOGC núm. 6268, de 5 de diciembre) y Canarias, Decreto $113 / 2015$, de 22 de mayo, por el que se aprueba el Reglamento de las viviendas vacacionales de Canarias (BOC núm., de 28 de mayo de 2015); Galicia, Decreto 12/2017, de 26 de enero, que establece la ordenación de apartamentos turísticos, viviendas turísticas y viviendas de uso turístico en la Comunidad Autónoma de Galicia (DOG núm. 29 de 10 de febrero); Madrid, Decreto 79/2014, de 10 de julio, por el que se regulan los apartamentos turísticos y las viviendas de uso turístico (BOCAM núm. 180, de 31 de julio); Navarra, Ley Foral 7/2003, de 14 de febrero, de turismo de Navarra (BON núm. 23 de 21 de febrero) Orden foral 80/2014, de 25 de septiembre, del Consejero de Cultura, Turismo y Relaciones Institucionales por la que se establece la obligación de hacer constar el código de inscripción en el Registro de Turismo de Navarra de las acciones de promoción, publicidad y comercialización que realicen las empresas, establecimientos y actividades turísticas en medios on line (BON núm. 194, de 3 de octubre); País Vasco, arts. 53 y ss. de la Ley 13/2016, de 28 de julio de turismo (BOPV núm. 152, de 11 de agosto); Valencia, Decreto 92/2009, de 3 de julio, que aprueba el reglamento regulador de las viviendas turísticas denominadas apartamento, villas, chalés ,bungalows y similares, y de las empresas gestoras, personas jurídicas o físicas, dedicadas a la cesión de su uso y disfrute (DOCV núm. 6051, de 7 de julio).

${ }^{24}$ Es interesante anotar que el DVFT recalca que al igual que en las viviendas turísticas de alojamiento rural previstas en el artículo 48 de la LTA y a diferencia de lo que ocurre con los establecimientos de alojamiento turístico, recogidos en el artículo 40 de la LTA dicha actividad no supone «con carácter general» la actividad principal de la persona propietaria.

${ }^{25}$ Pese a que la lista de requisitos recogidos en el artículo 6 del DVFT puede resultar exhaustiva, el Preámbulo del DVFT entiende que «dada la singularidad de este tipo de alojamiento, existe una proporcionalidad en la exigencia de requisitos [de manera que] los requeridos son más reducidos que los
} 
De acuerdo con ello, el DVFT regula en el artículo 6 las condiciones de uso, requisitos y equipamiento de la vivienda (alguno de los cuales van dirigidos a lograr la comodidad y la calidad puramente física de la estancia -mobiliario suficiente, sistema de refrigeración, enseres - mientras que otros pretenden garantizar la seguridad jurídica (hojas de quejas y reclamaciones ${ }^{26}$ ); asimismo, contiene una detallada regulación del régimen del contrato y las condiciones de acceso (artículo 7) y sobre la política de precios y reservas (artículo 8).

En cuanto a la seguridad pública, el DVFT se remite a lo dispuesto en el artículo 25 de la Ley 4/2015, de 30 de marzo, de Protección de la Seguridad Ciudadana $^{27}$, en la que se contemplan las actividades de hospedaje como relevantes para la seguridad. Ello se traduce en la imposición de obligaciones de registro documental e información sobre los viajeros que utilicen establecimientos de hospedaje, constituyendo una obligación de los titulares la cumplimentación del libro-registro, así como la presentación de los partes de entrada de viajeros conforme a lo establecido en la Orden INT/1922/2003, de 3 de julio, sobre libros-registro y partes de entrada de viajeros en establecimientos de hostelería y otros análogos. Dicha exigencia, se enmarca en el deseo de evitar que tales viviendas puedan usarse a modo de «refugios» para personas que realizan o han realizado actividades de, al menos, «dudosa legalidad», eludiendo cualquier tipo de control o seguimiento por parte de las autoridades al no dejar rastro alguno de su estancia.

\subsubsection{La protección del medio ambiente y el entorno urbano}

El DVFT hace expresa referencia al importante impacto que este tipo de actividad puede tener sobre el territorio y la convivencia vecinal ${ }^{28}$. Debe tenerse muy presente que la presencia de una VFT produce inevitables alteraciones en la vida diaria y tranquilidad de los vecinos como consecuencia del constante trasiego, o realización de actividades molestas (ruidosas o en horario de descanso) por parte de los viajeros que se encuentran disfrutando de unos días de ocio ${ }^{29}$.

que se imponen a otros alojamientos turísticos, tratándose de requisitos relacionados más directamente con la prestación del servicio, la dotación de una calidad básica en la oferta, así como la atención y el derecho a la información de las personas usuarias».

${ }^{26}$ Sobre la problemática que presentan las hojas de quejas y reclamaciones vid., GOSÁLVEZ PEQUEÑO, H., «El derecho del turista a reclamar: las "hojas de quejas y reclamaciones" en la legislación española, en especial en la legislación de defensa de los consumidores de Andalucía y en la normativa turística de Galicia y de Baleares», International Journal of Scientific Management and Tourism, Vol. 2 núm. 4 (2016,) págs. 51-68.

${ }^{27}$ Artículo 25.1: «Las personas físicas o jurídicas que ejerzan actividades relevantes para la seguridad ciudadana, como las de hospedaje, transporte de personas, acceso comercial a servicios telefónicos o telemáticos de uso público mediante establecimientos abiertos al público, comercio o reparación de objetos usados, alquiler o desguace de vehículos de motor, compraventa de joyas y metales, ya sean preciosos o no, objetos u obras de arte, cerrajería de seguridad, centros gestores de residuos metálicos, establecimientos de comercio al por mayor de chatarra o productos de desecho, o de venta de productos químicos peligrosos a particulares, quedarán sujetas a las obligaciones de registro documental e información en los términos que establezcan las disposiciones aplicables».

${ }^{28}$ El DVFT se remite a la exposición de motivos de la Ley 13/2011, de 23 de diciembre en la que se señala la necesidad de «una nueva cultura basada en la sostenibilidad» incidiendo en que «la ordenación del turismo tiene una significativa dimensión territorial, ambiental y paisajística» para añadir que «la oferta turística presenta otros componentes relacionados con el entorno donde se desenvuelve la vivienda de la persona usuaria de servicios turísticos, mereciendo especial atención aspectos como la correcta conservación de los recursos y la apropiada configuración de los espacios de destino turístico», además de la necesidad de proteger los recursos turísticos de acuerdo con el principio de sostenibilidad.

29 Estas molestias se han puesto de manifiesto por la jurisprudencia, así, por ejemplo, en la sentencia164/1996, de 16 de mayo, de la Audiencia Provincial de La Coruña (Ponente, Paredes Prieto), 
Precisamente ésta ha sido la razón que ha llevado a algunos municipios en los que esta actividad ha alcanzado una especial intensidad (dando lugar a la llamada, por algunos medios, «turismofobia $\left.{ }^{30} »\right)$ a dotarse de una normativa específica con el fin de paliar los citados efectos adversos; Así sucede, por ejemplo, en Barcelona que recientemente aprobado su Plan especial urbanístico para la regulación de las viviendas de uso turístico ${ }^{31}$ en el que se establecen unos requisitos específicos -muy rigurosos- con los que se trata de cercenar la multiplicación de este tipo de viviendas. Entre ellos figuran, entre otros, la obligación del titular de responder de forma inmediata, directa o indirectamente, en un plazo máximo de treinta minutos a cualquier requerimiento municipal a fin de dar soluciones a problemas convivenciales, de seguridad o salubridad que se pudieran producir; en el caso de que la vivienda se pretenda ubicar en un edificio sometido a régimen de propiedad horizontal, la certificación de los Estatutos de la comunidad de propietarios o, en caso de no contemplar éstos ninguna disposición o manifestación expresa en relación con esta actividad, acuerdo de la Junta de propietarios de la aceptación de la instalación de la vivienda en el edificio; la acreditación de que el edificio donde se pretende ubicar la vivienda no estuviera destinada a «uso de vivienda» a 1 de julio de 2015; o el aval o depósito en garantía del cumplimiento de las obligaciones establecidas en el plan, de acuerdo con lo establecido en la normativa municipal. Además, dicho Plan limita los lugares de la ciudad donde puede ofrecerse una vivienda de este tipo, previendo una precisa división en zonas («zonificación»), considerándose para su fijación «el efecto de agregación que estos tipos de establecimientos producen sobre la oferta de establecimientos de alojamiento turístico y del resto de establecimientos de alojamiento temporal, la relación de plazas ofertadas respecto de la población residente o el hecho de tratarse de ámbitos de la ciudad en proceso de desarrollo del planeamiento urbanístico».

En esta línea se sitúa, asimismo, la reciente Ley 6/2017, de 31 de julio, de modificación de la Ley 8/2012, de 19 de julio, del turismo de las Islas Baleares, mediante la que se pretende delimitar aquellas zonas aptas para llevar a cabo la comercialización turística de viviendas de uso residencial y limitar el número de plazas turísticas $^{32}$ o la Ordenanza reguladora del uso urbanístico de vivienda turística y alquiler

puede leerse: «Refutaba el demandado la alegada incomodidad o molestias que la actividad pudiera suponer para los demás moradores del edificio. Ciertamente que la calificación ha de referirse a los concretos vecinos del portal en el que se ubica el negocio del demandado y que consta de cinco plantas, pues, desde luego, no afecta en igual medida a los demás portales del inmueble. Y cabe concluir que la industria de hospedaje que el demandado explota en el piso de autos, conlleva unas molestias potenciales que exceden de las que la convivencia en un régimen de propiedad horizontal obliga a soportar, y que la prueba testifical practicada pone de relieve; así el uso intensivo del ascensor con carga y descarga de equipajes, la ocupación del portal con maletas y otros bultos, las frecuentes entradas y salidas de personas, el aumento de gastos en el consumo de luz y por reparaciones del ascensor que con frecuencia aparece deteriorado, hechos que los testigos afirman se conectan con el inicio de la actividad de hospedaje, al igual que el hecho de que la puerta de entrada al inmueble permanezca «casi siempre» abierta, etcétera. Hechos concretos que el demandado no desvirtúa con la prueba practicada a su instancia, y que desde luego se traducen en molestias para los demás moradores del inmueble y que se integran en la prohibición del número $3 .^{\circ}$ artículo $7 \mathrm{LPH}$ que impide a todo propietario desarrollar en su piso actividades incómodas para la finca».

${ }^{30} \mathrm{http}$ ://elpaissemanal.elpais.com/documentos/turismofobia/

${ }^{31}$ BO de Barcelona de 21 de abril de 2016.

${ }^{32}$ La zonificación se encomienda a los Consejos insulares de cada isla y al Ayuntamiento de Palma, concediéndoles para ello un plazo de doce meses, plazo durante el que entrará en vigor la moratoria en la concesión de nuevas licencias para la comercialización de viviendas turísticas, tango en viviendas residenciales en edificios plurifamiliares (lo que constituye una novedad) como en unifamiliares aisladas, 
de habitaciones en vivienda habitual para uso turístico, recientemente aprobada por del Ayuntamiento de San Sebastián ${ }^{33}$, que declara «zonas saturadas» la Parte Vieja y el puerto.

\subsection{Concepto de «viviendas con fines turísticos».}

El DVFT no delimita al inicio -aunque sí posteriormente- lo que deba entenderse por VFT; se limita a establecer de forma tautológica que su objeto es regular «las viviendas con fines turísticos como un servicio de alojamiento turístico», recurriendo a la práctica, siempre peligrosa, de definirlas por contraposición o exclusión con otras figuras.

De este modo, no precisa su objeto al definir lo que son las viviendas turísticas, sino por contraste a lo que no son; así, conforme a lo recogido en el artículo 2.2, no se consideran viviendas turísticas $\mathrm{y}$, por tanto, quedan excluidas del ámbito de aplicación del Decreto: a) las que por motivos vacacionales o turísticos se cedan sin contraprestación económica; b) las viviendas contratadas por un tiempo superior a dos meses, computados de forma continuada por una misma persona usuaria; c) las situadas en el medio rural que, en caso de que se destinen a alojamiento turístico se regularán por lo establecido en la Ley de Turismo de Andalucía (LTA) y en el Decreto 20/2002, de 29 de enero, de Turismo activo (DTA); d) los conjuntos formados por tres o más viviendas de una misma persona titular o explotadora ubicadas en un mismo inmueble o grupo de inmuebles contiguos o no, a los que será de aplicación la normativa andaluza sobre apartamentos turístico.

Ya el artículo 3 define las VFT como las «ubicadas en inmuebles, situadas en suelo de uso residencial y destinadas a ofrecer mediante precio un servicio de alojamiento de forma habitual y con fines turísticos» ${ }^{34}$.

De lo previsto en este precepto y de las exclusiones que se detallan en el apartado segundo del artículo 1, resultan las notas que integran, a modo de anverso y reverso, el concepto. Son las siguientes:

a) Las viviendas con fines turísticos se incluyen dentro de los servicios turísticos de alojamiento.

En particular, las VFT se incluyen entre los servicios de alojamiento turístico extra hotelero (artículo 28.1 a) de la LTA y artículo 1.1 del DVFT), y se regirán por lo dispuesto en la LTA, el DVFT, y demás normativa sectorial que resulte de aplicación (artículo 2 DVFT).

b) Las viviendas con fines turísticos deben estar ubicadas en un inmueble situado en suelo de uso residencial.

\footnotetext{
entre medianeras o apareadas. Hasta que no se concrete la nueva zonificación no se podrán presentar nuevas declaraciones responsables de inicio de actividad turística y, por tanto, no se concederán nuevas licencias para la comercialización de estancias turísticas.

${ }^{33}$ Ordenanza de 30 de agosto de 2017.

34 De forma más completa, el artículo 3 del Decreto 3/2017, de 16 de febrero, que regula los establecimiento de alojamiento en la modalidad de vivienda de uso turístico en la Comunidad de Castilla y León, define las viviendas de uso turístico como «pisos, casas, bungalós, chalets u otros inmuebles análogos, amueblados y equipados en condiciones de uso inmediato, que son comercializados o promocionados en canales de oferta turística para ser cedidos temporalmente y en su totalidad a terceros, de forma habitual, con fines de alojamiento turístico y a cambio de contraprestación económica».
} 
De modo criticable, y de forma análoga a otras normas autonómicas, el DVFT exige que las viviendas que se destinen a esta finalidad turística estén situadas en suelo de uso residencial. Ello implica que no podrán destinarse a tal fin las que estén situadas en suelo turístico, lo que implica, de facto, una medida a favor de los establecimientos de alojamiento tradicionales que son los situados en este tipo de suelo; esto, a juicio de la CNMC -que se pronuncia sobre esta cuestión en relación a idéntica previsión recogida en el Decreto 113/2015, de 22 de mayo, por el que se aprueba el reglamento de las viviendas vacacionales de la Comunidad de Canarias- constituye una de las restricciones más severas a la competencia que se impone a esta $\operatorname{actividad}^{35}$, pues «impacta en el mercado de dos maneras fundamentales. En primer lugar, excluye del mercado a operadores efectivos y potenciales, dado que impide que viviendas situadas en parte del territorio - en las que sí pueden competir hoteles y otro tipo de operadores turísticos - puedan competir y prestar servicios. En segundo lugar, esta exclusión no es neutral, ya que se basa en la localización de las mismas y, en particular, en si las viviendas están ubicadas o no en suelo turístico dentro de zonas o urbanizaciones turísticas. Este factor intensifica el efecto restrictivo, dado que la localización es un atributo fundamental en los establecimientos de alojamiento turístico para competir $(\ldots) \gg$.

El encapsulamiento de las VFT a zonas residenciales ha empezado a generar problemas en algunas ciudades especialmente turísticas (como Barcelona) que, ante las constantes quejas de los vecinos, se han visto impelidas a la adopción de ciertas medidas adicionales, con el fin de limitar la proliferación de este tipo de viviendas restringiendo -e incluso excluyendo- las que pueden establecerse ciertas zonas de la ciudad; de esta forma, se ha originado en algunos casos un sentimiento de hostilidad hacia los visitantes - hasta ahora inédito en nuestro país- y otros efectos paralelos como la extraordinaria subida del precio de alquiler de viviendas para residentes.

c) Su finalidad es ofrecer mediante precio un servicio de alojamiento.

Se excluyen del ámbito del Decreto otras posibilidades que incluyeran alojamiento sin pago de precio (p.ej., el intercambio de viviendas)- excluidas de forma expresa en el apartado a) del artículo 1.2 del DVFT- u otro tipo de contraprestación (p.ej. alojamiento a cambio de enseñanza de idiomas u otra previamente definida por las partes: musical, culinaria) o el -ya desvirtuado- couchsourfing (alojamiento gratuito en el sofá de una casa a turistas de paso $)^{36}$, entre otras.

d) El alojamiento en viviendas de uso turístico no constituye la actividad principal del propietario.

El DVFT destaca en su Preámbulo ${ }^{37}$ que -al igual que en las viviendas turísticas de alojamiento rural previstas en el artículo 48 de la LTA y a diferencia de lo que ocurre con los establecimientos de alojamiento turístico, recogidos en el artículo 40 de la LTAel alojamiento en VFT no supone, «con carácter general», la actividad principal de la

\footnotetext{
35 Informe sobre el Decreto 113/2015, de 22 de mayo, por el que se aprueba el Reglamento de las viviendas vacacionales de la Comunidad autónoma de Canarias, LA/03/15, pág. 11.

${ }^{36}$ La finalidad lucrativa se contempla también de forma expresa en la Exposición de Motivos de la Ley 6/2017, de 31 de julio, de modificación de la Ley 8/2012, de 19 de julio, del turismo de las Islas Baleares , relativa a la comercialización de estancias turísticas en viviendas y en cuyo apartado II puede leerse que «Es necesario observar en todos los casos, que se exige finalidad lucrativa, lo cual excluye del concepto de vivienda comercializada turísticamente supuestos como la cesión temporal y gratuita de vivienda y los intercambios de viviendas con finalidades turísticas, entre otros».

${ }^{37}$ Véase el párrafo $4^{\circ}$.
} 
persona propietaria. La expresión entrecomillada hace suponer que se trata de una previsión no obligatoria; por tanto, la norma (la regla general) es que dicha actividad no es la principal del propietario, aunque, según lo expuesto, no se excluye que pueda serlo.

\section{e) Deben destinarse a ofrecer alojamiento de forma habitual y con una finalidad turística}

La habitualidad y la finalidad turística se presumen por el hecho de ofrecer la vivienda a través de canales de oferta turística, debiendo entenderse por tales las agencias de viaje, las empresas que medien u organicen servicios turísticos y los canales en los que se incluya la posibilidad de reserva de alojamiento ${ }^{38}$. El fin de esta disposición parece ser el deseo de poner punto y final a la actividad de ciertas páginas que desarrollan su actividad por Internet, escapando de los controles y filtros que operan para las agencias tradicionales (no virtuales).

En Andalucía, a diferencia de otras Comunidades Autónomas, no se concreta la frecuencia requerida para que la actividad se considere habitual, bastando, como se ha anticipado con que la vivienda «sea comercializada o promocionada en canales de oferta turística»; Entiendo que hubiera sido conveniente fijar un criterio más preciso como se ha hecho en otras regiones (como Asturias), en las que se puntualiza que para que exista la habitualidad basta con el que el servicio se preste tan sólo una vez al año, o bien como Castilla y León, donde la habitualidad existe cuando se facilite alojamiento en una o más ocasiones dentro del mismo año natural por tiempo que exceda de un mes ${ }^{39}$, o, en su caso, Cataluña, donde se considera que hay cesión reiterada cuando ésta se produce dos o más veces dentro de un año.

f) En el caso de tratarse de una misma persona titular o explotadora, su número no podrá exceder de dos viviendas, situadas en el «mismo inmueble o grupo de inmuebles contiguos o no».

Si el número de viviendas excediera del indicado (es decir, cuando se trate de tres) resultaría de aplicación la normativa sobre apartamentos turísticos recogida en el Decreto 194/2010, de 20 de abril (DAT). La referencia al número de alojamientos resulta pues fundamental para delimitar el ámbito de aplicación de una y otra normativa (VFT y apartamentos) $)^{40}$.

No existe problema en determinar qué debe entenderse por viviendas situadas en el mismo inmueble, la dificultad surge a la hora de interpretar lo que debe entenderse por «grupo de inmuebles contiguos o no». ${ }^{41}$

\footnotetext{
${ }^{38}$ De forma más precisa, el apartado b) del artículo 3 del Decreto 48/2016, de 10 de agosto, de Viviendas vacacionales y viviendas de uso turístico del Principado de Asturias incluye dentro de los canales de oferta turística a «las empresas de intermediación turística, como agencias de viajes y centrales de reserva, incluidos los canales de intermediación virtuales; páginas webs de promoción, de alquiler, marketplaces; cualquier canal que permita la posibilidad de reserva de alojamiento o realice publicidad por cualquier medio o soporte de oferta de alojamiento con connotaciones turísticas».

${ }^{39}$ Artículo 4 c) del Decreto 3/2017, de 16 de febrero.

${ }^{40}$ Conforme al artículo 4.3 del DAT: «No tendrán la consideración de empresas explotadoras los titulares de uno o dos apartamentos ubicados en un mismo inmueble o grupo de inmuebles que ofrezcan mediante precio el servicio de alojamiento de forma habitual y con fines turísticos, entendiéndose, en este caso, que se destinan a viviendas con fines turísticos».

${ }^{41}$ En la página de la Junta de Andalucía en la que se facilita información sobre los trámites administrativos para ofrecer una VFT se aclara que se considera que los inmuebles son contiguos si están

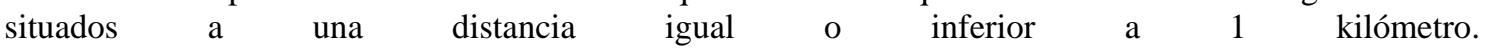


g) Su contratación no podrá exceder de dos meses computados de forma continuada por la misma persona usuaria.

Este apartado plantea, en una primera aproximación, varias consideraciones: la justificación de la fijación de este plazo máximo, el cómputo del mismo, la exigencia de que estos dos meses sean «continuados» $\mathrm{y}$, finalmente, la inexistencia de un plazo mínimo.

En cuanto a la última cuestión, Andalucía se sitúa en la línea sugerida por la CNMC y la Federación Española de Asociaciones de Viviendas de Uso Turístico y Apartamentos Turísticos (FEVITUR) y se desmarca de la línea seguida por otras Comunidades Autónomas (p.ej. Madrid) al no prever un plazo mínimo de estancias, opción que, por lo demás, ha sido recientemente apoyada por los Tribunales: en efecto, el Decreto 79/2014, de 10 de julio por el que se regulan los apartamentos turísticos y las viviendas de uso turístico en la Comunidad de Madrid exigía en su artículo 17.3 la contratación de la vivienda para una estancia que no podía ser inferior a cinco días.; Dicha previsión ha sido impugnada por la Federación Española de Viviendas de uso turístico y apartamentos turísticos (FEVITUR) y por la CNMC. Uno y otro recurso han sido resueltos recientemente por las SSTSJ de Madrid 303/2016, de 2 de junio y 291/2016, de 31 de mayo. En esta última el Tribunal razona que: «(...) tal finalidad como tal (protección del usuario turístico del servicio) ya se contemplaba en otros preceptos de la norma, al establecer el artículo 5 del Decreto impugnado que los apartamentos turísticos y las viviendas de uso turístico deberán cumplir las normas sectoriales aplicables en la materia, con especial mención de las normas de seguridad, urbanismo, accesibilidad, sanidad y medio ambiente. Así pues, la finalidad de protección del usuario del servicio no parece desprenderse de la limitación de su estancia a periodos mayores de cinco días, porque no se considera que éste se encuentre más protegido en sus derechos por el hecho de que se limite su estancia temporal en la vivienda. Tampoco la medida aparece como proporcionada respecto del fin que se expresa como determinante de aquella porque no se demuestra en modo alguno que sea menos gravosa para el sector en la consecución del fin que se afirma responde. Más bien, lo que se desprende de tal limitación es la restricción de la competencia (...) con respecto solo de una modalidad de alojamiento turístico, acreditándose, por el contrario, a través de un informe aportado por la Abogacía del Estado basado en la encuesta realizada por el Instituto Nacional de Estadística sobre la ocupación hotelera y estancia media de los viajeros por provincias, categorías y meses, que tal demanda turística es menor de cinco días en la mayoría de las ocasiones. De forma que al demandarse el alojamiento turístico cuantitativamente en mayor medida para estancias más cortas de esos cinco días (fines de semana esencialmente) resulta perjudicado únicamente el sector de viviendas de uso turístico, único al que se impone tal restricción en la libre concurrencia, frente a las otras modalidades de alojamiento en relación con las cuales no se establece limitación temporal alguna».

Como plazo máximo se fija el de dos meses; No precisa el DVFT qué ocurre en caso de que la duración excediera del plazo antedicho, aunque cabe afirmar que en tal caso la actividad deberá calificarse jurídicamente de otro modo y aplicarse la normativa que corresponda. Ello significa, en definitiva, que una misma vivienda, en función del plazo por el que se contrate puede estar sometida a regímenes diversos.

http://www.juntadeandalucia.es/turismoydeporte/opencms/areas/turismo/registro-de-turismo/preguntasfrecuentes-sobre-viviendas-con-fines-turisticos/ 
El cómputo del plazo se hará de fecha a fecha, siendo de aplicación las normas generales sobre plazos recogidos en el Código Civil, pues estamos en presencia de un contrato de esta naturaleza (civil) $^{42}$, si bien con un contenido condicionado administrativamente. Con el fin de evitar confusiones sobre fechas, el artículo 7 del DVFT prevé que toda persona usuaria recibirá en el momento de su recepción en la vivienda «un documento a modo de contrato» en el que entre otros datos deberá figurar el nombre de la persona o entidad explotadora y «las fechas de entrada y salida».

\section{ELEMENTOS PERSONALES: EL PROPIETARIO DE LA VIVIENDA, EL EXPLOTADOR, EL INTERMEDIARIO Y EL USUARIO}

En este contrato pueden aparecer implicadas hasta cuatro personas: el propietario de la vivienda, el explotador, el intermediario y el usuario. Los tres primeros pueden ser personas físicas o jurídicas, mientras que los usuarios sólo podrán ser personas físicas.

El DVFT presume la identidad entre el propietario y explotador, salvo que en la declaración responsable -a la que se hará inmediata referencia- figure como explotador una física o jurídica determinada para lo que deberá disponer del correspondiente título jurídico habilitante ${ }^{43}$.El titular de la vivienda (sea el propietario-explotador o el explotador caso de que se trate de personas diferentes) será responsable ante la Administración y ante las personas usuarias de la correcta prestación del servicio

El DVFT no contiene una enumeración detallada de los derechos y obligaciones, para lo que se remite a las previsiones de la LTA, con dos menciones específicas: a) la obligación de los usuarios de atenerse a las «reglas de convivencia» (artículo 2.5 DVFT) y b) la prohibición de sobrecontratación (artículo 2.6 DVFT) ${ }^{44}$.

En relación a la obligación de los usuarios de atender a las reglas de convivencia, destaca la -como poco- polémica potestad que se concede al propietario y/o explotador de «denegar la permanencia de las personas usuarias y requerir el abandono de la vivienda en el plazo de 24 horas» en caso de que el usuario las quebrante. Como se advierte, la problemática afecta tanto a su ejecución práctica como su intrínseca legitimidad -que se basa en criterios tan vagos como la determinación de lo que signifique infringir «las normas de convivencia», y que, como se ha dicho, serán variables en cada caso. Esta referencia a las normas de convivencia obliga a estar -y así se precisa en algunas normas autonómicas- a lo que se prevea en los estatutos de la comunidad de propietarios donde la vivienda esté ocupada o los usos de convivencia y orden público, con el fin evitar el riesgo de abusos por el explotador con una paralela desprotección de los usuarios que pueden ver el acceso restringido a la vivienda por este motivo o ser expulsados de ella.

\footnotetext{
42 Sobre la naturaleza civil de este contrato vid., MARTOS CALABRÚS, M ${ }^{\mathrm{a}}$ A., "El contrato de arrendamiento de vivienda vacacional tras la reforma del artículo 5 de la LAU por la Ley 4/2013", Revista de Derecho Civil vol. I, núm. 1 (enero-marzo 2014), pág. 92.

${ }^{43}$ El DVFT no concreta más, pero otras normas autonómicas ofrecen un mayor grado de detalle sobre los requisitos de la persona comercializadora. Así, p.ej. el artículo 50.10 de la Ley 8/2012, de 19 de julio, de Turismo de las Islas Baleares dispone que la «tiene que cumplir todos los requerimientos normativos que puedan ser exigibles para ejercer la actividad empresarial; los de la legislación laboral, si tiene personal contratado; los requerimientos de carácter tributario contenidos en la normativa específica».

${ }^{44}$ El tenor literal de este artículo es idéntico al del artículo 12 del Decreto 47/2004, de 10 de febrero, de establecimientos hoteleros de Andalucía (BOJA núm. 42, de 2 de marzo).
} 
En este sentido, a diferencia de lo que ocurre en otras normas autonómicas (p.ej. Aragón) el DVFT no explicita -caso de edificio en régimen de propiedad horizontalque para que pueda iniciarse la actividad de alojamiento en una VFT es preciso que dicha actividad no aparezca como prohibida en los Estatutos de la comunidad del edificio o, si no se especificara nada al respecto en los mismos, el acuerdo de la Junta de $\operatorname{propietarios}^{45}$. La jurisprudencia viene entendiendo que debe existir una "mínima limitación", recogida en el título constitutivo del régimen de propiedad horizontal, o los Estatutos, pues, de no existir, las facultades dominicales del propietario no pueden ser restringidas ${ }^{46}$.

Finalmente, con independencia de que aparezca como explotador el propietario de la vivienda u otra persona (física o jurídica), la comercialización podrá realizarse directamente o por intermediario.

\section{ELEMENTOS REALES: LA VIVIENDA}

El DVFT extiende su ámbito de aplicación tanto al supuesto en que la vivienda cualquiera que sea su tipología- ${ }^{47}$ se ceda en su totalidad, como si se cede por habitaciones. Esta última posibilidad constituye una notable singularidad de la normativa regional-que, de este modo, se sitúa en la línea defendida por la CNMC- ya que la cesión por habitaciones no se permite en la mayoría de las normas autonómicas ${ }^{48}$, excepción que -en mi opinión- encuentra difícil justificación, incluso si se invoca la propia inercia del sistema, por cuanto la resistencia al cambio no puede justificarse ante un innegable cambio de hábitos de los usuarios.

En cualquier caso, para la cesión por habitaciones se exige (apartado b) del artículo 5) que la persona propietaria resida en ella, permitiéndose que en este último supuesto puedan utilizarse las «denominaciones internacionalmente reconocidas para este tipo de alojamiento, denominaciones que no se especifican, aunque parecen apuntar

\footnotetext{
${ }^{45} \mathrm{Si}$ se recoge, por ejemplo, en el apartado d) del artículo 27 del Decreto 48/2016, de 10 de agosto, de viviendas vacacionales y viviendas de uso turístico de Asturias que entre las obligaciones de las empresas explotadoras de las viviendas incluye «acreditar que el destino de la vivienda vacacional o de uso turístico no esté prohibido por la ordenación urbanística de la zona donde se encuentre o por los Estatutos de la comunidad de propietarios debidamente inscritos en el Registro de la Propiedad en edificios sometidos al régimen de propiedad horizontal. En el caso de existir esta última prohibición deberá acreditarse la existencia de autorización expresa, por escrito, de la misma».

${ }^{46}$ Conforme a la STS de 12 de septiembre de 2013 (rec. 1347/2010): «la doctrina de esta Sala es prácticamente unánime (SSTS 30 de diciembre de 2010, 23 de febrero de 2006, 20 de octubre de 2008) al considerar que la mera descripción del inmueble no supone una limitación del uso o de las facultades dominicales, sino que la eficacia de una prohibición de esta naturaleza exige de una estipulación clara y precisa que la establezca.

Los copropietarios no pueden verse privados de la utilización de su derecho a la propiedad como consideren más adecuado, a no ser que este uso esté legalmente prohibido o que el cambio de destino aparezca expresamente limitado por el régimen de dicha propiedad horizontal, su título constitutivo o su regulación estatutaria».

${ }^{47}$ A diferencia de otras normas autonómicas, el DVFT no especifica el tipo de vivienda. Con esta fórmula abierta se las evitan las inevitables exclusiones que lleva aparejada toda enumeración. A diferencia de la norma andaluza, la Ley 13/2016, de 28 de julio, de Turismo del País Vasco, precisa que son viviendas para uso turística las viviendas «cualquiera que sea su tipología», que se ofrezcan o comercialicen como alojamiento por motivos turísticos o vacacionales (...).

${ }^{48}$ También se permite la cesión de habitaciones en Euskadi, artículo 53.7 de su reciente Ley de Turismo (Ley 13/2016, de 28 de julio, BOE núm. 219, de 10 de septiembre) o en Asturias, artículo 12 del Decreto 48/2016, de 10 de agosto, de viviendas vacacionales y viviendas de uso turístico (BOPA núm. 191, de 17 de agosto).
} 
a los populares bed and breakfast - $B \& B$-o bed and brekky. A diferencia de lo que ocurre en otras normas autonómicas ${ }^{49}$, el DVFT no limita el número de habitaciones que una misma persona puede comercializar, por lo que podría argumentarse que, en principio, es lícito que una misma persona pueda ofrecer habitaciones en más de una vivienda.

El DVFT también recoge el número de plazas de que pueden disponer este tipo de alojamientos -que se concretarán en la licencia de ocupación o documento equivalente- sin fijar un número mínimo, pero sí un máximo que serán quince plazas -en el entendimiento de que cada plaza equivale a una cama (o dos, en caso de cama doble) y excluidas las cunas- cuando el uso de la vivienda sea completo, o de seis cuando el uso sea por habitaciones, sin que en, en ninguno de los dos casos, pueda exceder de cuatro plazas por habitación. Por último, a diferencia de lo que ocurre en otras normas autonómicas $^{50}$, el DVFT no prevé la superficie mínima de las habitaciones según las plazas.

En cualquier caso, como se anticipó, las VFT deberán cumplir con una serie de requisitos (muebles y enseres, limpieza, botiquín de primeros auxilios, libro de quejas y reclamaciones...), requisitos que, por cierto, varían de forma notable según la norma autonómica de que se trate, y que, por otro lado, aproximan este tipo de establecimientos a los hoteleros. En Andalucía, se enumeran en el artículo 6 del DVFT $^{51}$, si bien debe entenderse que existe la posibilidad de obtener la dispensa de alguno de ellos por parte de la Administración turística en ciertos casos excepcionales.

\footnotetext{
${ }^{49}$ El artículo 54. 3 de la Ley 13/2016, de 28 de julio, de Turismo de Euskadi dispone que «Una misma persona titular no podrá, en ningún caso, ofertar o comercializar habitaciones en más de una vivienda, en cuyo caso estos últimos alojamientos serán considerados como otros tipos de establecimientos.

Reglamentariamente se establecerá el número máximo de plazas que podrán ofertarse en una misma vivienda. Si se supera la oferta del número de plazas turísticas permitidas, el alojamiento será considerado como un establecimiento hotelero, debiendo cumplir todos los requisitos y obligaciones exigidas a este tipo de establecimientos».

${ }^{50}$ Artículo 8 del Decreto 80/2015, de 5 de mayo, del Gobierno de Aragón por el que se aprueba el Reglamento de las viviendas de uso turístico en Aragón.

${ }^{51}$ Son los siguientes:

a) Disponer de licencia de ocupación, y cumplir en todo momento con las condiciones técnicas y de calidades exigibles a las viviendas.

b) Las habitaciones tendrán ventilación directa al exterior o a patios y algún sistema de oscurecimiento de las ventanas. Este requisito no será exigible cuando la vivienda o el edificio en el que se integra esté catalogado como Bien de Interés Cultural y el nivel de protección impida realizar algún tipo de obra, modificación o intervención que sea necesaria para cumplir con el requisito.

c) Estar suficientemente amuebladas y dotadas de los aparatos y enseres necesarios para su uso inmediato y acorde al número de plazas de que dispongan.

d) Refrigeración por elementos fijos en las habitaciones y salones, cuando el período de funcionamiento comprenda los meses de mayo a septiembre, ambos inclusive. Si el periodo de funcionamiento comprende los meses de octubre a abril, ambos inclusive, deberán contar con calefacción. Este requisito no será exigible cuando la vivienda o el edificio en el que se integra esté catalogado como Bien de Interés Cultural y el nivel de protección impida realizar algún tipo de obra, modificación o intervención que sea necesaria para cumplir con el requisito.
}

e) Botiquín de primeros auxilios.

f) Disponer de información turística, en soporte físico o electrónico, de la zona, zonas de ocio, restaurantes y cafeterías, comercios y tiendas de alimentos, los aparcamientos más próximos a la vivienda, servicios médicos existentes en la zona, medios de transporte urbano, plano de la localidad y guía de espectáculos.

g) Todas las viviendas dispondrán de Hojas de Quejas y Reclamaciones a disposición de las personas usuarias, y de cartel anunciador de las mismas en un lugar visible dentro de la vivienda.

h) Limpieza de la vivienda a la entrada y salida de nuevos clientes.

i) Ropa de cama, lencería, menaje de casa en general, en función a la ocupación de la vivienda y un juego de reposición. 


\section{1. ¿Tienen las viviendas de uso turístico la consideración de «establecimientos abiertos al público»?}

Pese a que las VFT no tienen la consideración de establecimientos turísticos, sino de viviendas privadas en las que se ofrece el servicio turístico de alojamiento, una de las primeras conclusiones que emergen tras la lectura de las previsiones del DVFT es la alteración de la naturaleza jurídica de las viviendas que se dediquen a esta actividad, de las que no puede predicarse el carácter privado $^{52}$-reservado inherente al domiciliopara entrar en una categoría especial que se asemeja -aunque no se identifica- a la de los establecimientos abiertos al público. Así resulta de lo dispuesto en su artículo 2.3, al disponer lo siguiente: «El acceso a las viviendas con fines turísticos no podrá restringirse por razones de nacimiento, raza, sexo, religión, opinión u otra circunstancia personal o social».

De este modo, mientras que los arrendamientos de temporada siguen rigiéndose por la normativa de Arrendamientos Urbanos, no perdiendo la vivienda sobre la que recaen la cualidad de privada y conservando el arrendador la plena disposición sobre la elección del inquilino, no ocurre lo mismo con las VFT. Así resulta de la imposición de una serie de requisitos -supervisables en vía administrativa, y cuyo incumplimiento puede dar lugar a la consiguiente responsabilidad- y, en particular, el constituido por la prohibición de que el acceso a las viviendas se restrinja por razones de nacimiento, raza, sexo, religión, opinión u otra circunstancia personal o social," (artículo 2.3 del DVFT). De ello resulta que la oferta de la vivienda (que "se abre al público") supone el deseo de los titulares de contratar, en principio, con cualquiera que acepte sus precios y condiciones de manera que «aunque no exista propiamente una obligación de contratar (...) renuncian a seleccionar con criterios individuales a su clientela» ${ }^{53}$. Dicho acceso no podrá limitarse sino por causas concretas y determinadas, con la posible aparición del conflicto entre el derecho de los usuarios a acceder a dichos locales y el de los titulares a restringirlo invocando el derecho de admisión ${ }^{54}$.

En esta línea se sitúa la reciente STSJ de Madrid 303/2016, de 2 de junio ${ }^{55}$, que resuelve el recurso por la Federación española de asociaciones de viviendas de uso turístico y apartamentos turísticos (FEVITUR) contra diversos apartados del Decreto $79 / 2014$, de 10 de julio, por el que se regulan los apartamentos de turísticos y las viviendas de uso turístico de Madrid. Afirma el Tribunal, en el FJ $5^{\text {a }}$ de la sentencia, lo

\footnotetext{
j) Facilitar a las personas usuarias un número de teléfono para atender y resolver de forma inmediata, cualquier consulta o incidencia relativa a la vivienda.

k) Tener a disposición de las personas usuarias información e instrucciones de funcionamiento de electrodomésticos u otros dispositivos que lo requieran para su correcto uso.

1) Informar a las personas usuarias de las normas internas relativas al uso de las instalaciones,

dependencias y equipos de la vivienda, así como la admisión y existencia de mascotas en la vivienda, restricciones para personas fumadoras, así como las zonas de uso restringidos.

${ }^{52}$ En cambio, para DE LA ENCARNACIÓN, A. $\mathrm{M}^{\mathrm{a}}$, «El alojamiento colaborativo: viviendas de uso turístico y plataformas virtuales», REALA núm. 5 (enero-junio 2016), pág. 5, «las principales diferencias con el denominado «alojamiento turístico» son, por un lado, la habitualidad en la prestación, ya que las empresas de alojamiento se dedican de forma profesional y habitual a esta actividad y, por otro, que no se trata de un establecimiento abierto al público».

${ }^{53}$ Vid. ALFARO, J., «Autonomía privada y derechos fundamentales», en Anuario de Derecho civil, Tomo XLVI, Fasc. 1 (1993), pág. 78.

${ }^{54}$ Un estudio en profundidad sobre la problemática que plantea el llamado "derecho de admisión" puede encontrarse en ROCA FERNÁNDEZ-CASTANYS, M ${ }^{\mathrm{a}}$ L., «Régimen jurídico-administrativo del derecho de admisión en establecimientos públicos. Especial referencia al caso andaluz", RArAP núm. 36 (2010), págs. 313-358

${ }_{55}$ Rec. 1159/14.
} 
siguiente: «considera la parte actora que es ilegítima la exigencia introducida por el primer inciso del apartado decimoctavo, porque sostiene que las viviendas de uso turísticos son domicilios privados y no establecimientos turísticos y, también considera que el derecho a la inviolabilidad del domicilio permitiría a los propietarios de esas viviendas negar el acceso a quien tuvieren por conveniente. En primer lugar, debe decirse que los argumentos de la parte actora que en los puntos anteriores se acogían a reclamar la equiparación con el resto de establecimientos hosteleros, en este punto de la impugnación pretenden sin embargo la equiparación con los domicilios privados y reclama el mismo tratamiento y derechos a ellos vinculados. Tal actitud revela la incongruencia del planteamiento. El propietario de una vivienda, al acogerse a esta modalidad de explotación de su vivienda abierta al público, debe también aceptar voluntariamente que deban modularse los derechos de que dispone respecto de los que le corresponden cuando la misma se destina a domicilio particular, porque ya no se estaría protegiendo la intimidad personal y familiar del titular, sino que prevalecen las cuestiones implicadas con su explotación hotelera. Por ello las disposiciones ahora discutidas parecen legítimas y perfectamente equiparables con las que se exigen, y aún con mayor intensidad, a otros establecimientos donde se prestan servicios turísticos donde, aunque esté reconocido el derecho de admisión (que no se niega tampoco a estos establecimientos) ello no supone que sea posible efectuar discriminación del tiempo de la que además está expresamente proscrita en el artículo 14 de la Constitución española».

\section{EI INICIO DE LA ACTIVIDAD: LA DECLARACIÓN RESPONSABLE Y LA INSCRIPCIÓN EN EL REGISTRO DE TURISMO.}

\subsection{La declaración responsable}

Como se ha dicho, las viviendas turísticas se configuran como establecimientos abiertos al público. Además, desarrollan una actividad de interés general. ${ }^{56}$ Pues bien, precisamente la calificación de su actividad como de interés general, justifica que, aun siendo privada la vivienda, deba existir una intervención administrativa que se traduce en el necesario cumplimiento de una serie de obligaciones de las que se hace depender que se otorguen o no las correspondientes autorizaciones o licencias para el inicio de la actividad. Uno de los objetivos principales de dicha intervención es la protección de los consumidores y usuarios; pero a este objetivo principal se añade el compromiso asumido por los poderes públicos de asegurar un adecuado funcionamiento del sector, de manera que éste pueda cumplir el fin económico-social que le corresponde ${ }^{57}$.

\footnotetext{
${ }^{56}$ Como se ha dicho, la mayor parte de las normas autonómicas utilizan, imprecisamente, el término de «establecimientos públicos» (en vez del de establecimientos privados abiertos al público). No obstante, existen algunas loables excepciones. Tal es, por ejemplo, el caso del Decreto aragonés 153/1990, de 11 de diciembre (BOA núm. 151, de 24 de diciembre). que aprueba el Reglamento que establece las normas de construcción e instalación de hoteles para su clasificación en esta Comunidad, cuyo artículo 2 dispone que los establecimientos hoteleros serán considerados como «establecimientos comerciales abiertos al público».

57 Como señaló con gran acierto hace ya más de cuarenta años RODRIGUEZ-PIÑERO BRAVOFERRER, M., «La intervención administrativa en la empresa hotelera», en Primer Congreso Ítaloespañol de profesores de Derecho administrativo. Sevilla, 1966. Imprenta del Ministerio de Información y Turismo. Madrid, 1970, pág. 207- « (...) este dirigismo económico reglamentario indica la relevancia pública de la actividad hotelera privada, que el interés público requiere empresas hoteleras eficientes y adecuadas» RODRIGUEZ-PIÑERO BRAVO-FERRER, M., «La intervención administrativa en la
} 
A este respecto, deben tenerse en cuenta las importantes modificaciones acaecidas en la materia como consecuencia de la trasposición de la Directiva 2006/123/CE del Parlamento Europeo y del Consejo, de 12 de diciembre, relativa a los servicios del mercado interior (en adelante, Directiva de Servicios). De este modo, las Comunidades Autónomas han dictado normas ${ }^{58}$ en las que se modifican diversas leyes y reglamentos, sustituyendo determinadas autorizaciones y licencias por otros medios de control menos estrictos (declaraciones responsables y comunicaciones previas).

Así ocurre con las viviendas turísticas en Andalucía donde para poder iniciar la prestación del servicio y la correspondiente publicidad basta con formalizar la correspondiente declaración responsable con el contenido que especifica el artículo $9.1^{59}$; Desde el momento en que la declaración responsable se presente en el Registro, se puede iniciar la prestación del servicio.

Como es lógico, cualquier alteración o modificación de los datos recogidos en la declaración responsable tendrán que ser comunicados a la Consejería competente en materia de turismo. La falta de presentación de dicha declaración determina la consideración de la actividad como clandestina y constituye -conforme a lo dispuesto en la LTA (artículo 71.1)- infracción grave sancionable con multa de 2.001 a 18.000 euros y posible sanción accesoria de suspensión del ejercicio de servicios turísticos o la clausura temporal del establecimiento por un periodo inferior a seis meses.

\subsection{La inscripción en el Registro de Turismo, número de registro, placa identificativa y clasificación.}

El artículo 9 del DVFT recoge en sus apartados 3 y 4 la inscripción de oficio de las VFT en el Registro de Turismo de Andalucía y la publicación del código alfanumérico (código que habrá de indicarse en «toda publicidad o promoción realizada por cualquier medio»). Las exigencias de ambos requisitos han sido muy criticadas por la CNMC que ve en ellos un exceso de trámites administrativos que suponen una carga regulatoria que pueden desincentivar la oferta.

El DVFT no recoge, en cambio, la necesidad de placa distintiva previsto en otras normas autonómicas (p.ej. Castilla León o Aragón) -y también criticado por la $\mathrm{CNMC}^{60}{ }_{-}$ni la obligación de suscribir una póliza de seguro que cubra la responsabilidad civil $^{61}$ por los daños corporales o materiales que puedan sufrir las

empresa hotelera», en Primer Congreso Ítalo-español de profesores de Derecho administrativo. Sevilla, 1966. Imprenta del Ministerio de Información y Turismo. Madrid, 1970, pág. 207

${ }^{58}$ Son el Decreto 80/2010, de 30 de marzo (BOJA núm. 69, de 30 de marzo) y la Ley

${ }^{59}$ Conforme a dicho artículo, el contenido mínimo (luego, pueden añadirse otros datos o documentos) de la declaración responsable será el siguiente:

a) Los datos correspondientes a la identificación de la vivienda, incluida su referencia catastral y su capacidad en función de la licencia de ocupación o documento equivalente.

b) Los datos de la persona propietaria y domicilio a efectos de notificaciones.

c) Identificación de la persona o entidad explotadora y título que la habilite, en caso de que no fuera la persona propietaria de la vivienda.

${ }^{60}$ A juicio del organismo regulador este requisito (la placa distintiva junto con las demás exigencias adicionales) «elevan los costes de entrada, obstaculizan la diferenciación y limitan la competencia en variables de precio y no precio»; A su juicio «Elevar los costes fijos para los entrantes, ya sea a través de comportamientos estratégicos o de cambios en la normativa, es un mecanismo restrictivo de la competencia que muchas veces llevan a cabo operadores incumbentes para desincentivar la entrada en un mercado y erosionar la competencia» (Informe económico sobre... cit. pág. 16).

${ }^{61}$ Obligación que se explicita, por ej. en el artículo 50.16 de la Ley 8/2012, de 19 de julio de Turismo de las Islas Baleares (BOIB núm.- 106, de 21 de julio). 
personas usuarias de las viviendas durante su estancia y, en caso de que se trate de viviendas sometidas al régimen de propiedad horizontal, seguro que debe entenderse exigible siempre que exista intermediario al amparo de lo dispuesto en el artículo 39 de la $\operatorname{LTA}^{62}$.

Por último, a diferencia de lo previsto en otras normas autonómicas, el DVFT no realiza -en esta línea se sitúa la mayoría de las normativas- una clasificación de las VFT por categorías $^{63}$; ello puede deberse a que se considera suficiente la información que reciben los usuarios a través de los canales a través de los que conocen y contratan la vivienda, en los que, además de las fotografías e información sobre ésta, es común que se reflejen las opiniones de otros usuarios ${ }^{64}$.

\section{EL CONTRATO}

El artículo 7 del DVFT contiene algunas previsiones mínimas sobre el contenido del contrato, al exigir que en este consten, al menos: el nombre de la persona o entidad explotadora de la vivienda, el código alfanumérico de inscripción de la VFT en el Registro de turismo de Andalucía, el número de personas que van a ocupar la vivienda, las fechas de entrada y salida, el precio total de la estancia y el número de contacto. Dicho documento, una vez firmado por la persona usuaria, deberá conservarse por la persona o entidad explotadora estando a disposición de la Administración de la Junta de Andalucía durante un año y teniendo valor de prueba a efectos administrativos y la consideración de contrato. Como en el caso de los libros registro, nos encontramos en este caso con una clara manifestación del deseo de proteger la seguridad y el orden público, así como una garantía para los propios usuarios; Se configura, de este modo, como un contrato con un contenido peculiar, con un contenido fuertemente administrativizado, que reduce de forma notable la libertad de las partes.

Asimismo, el DVT recoge en su artículo 8 una serie de previsiones sobre el precio y las reserva y anticipos, que se regirán, en primer lugar, por lo pactado entre las partes, permitiéndose, si no se hubiera hecho así que las personas o entidades explotadoras puedan exigir que al hacer la reserva efectúen un anticipo del precio en

\footnotetext{
${ }^{62}$ Dispone dicho precepto que «De conformidad con lo establecido en la Ley 17/2009, de 23 de noviembre, sobre el libre acceso a las actividades de servicios y su ejercicio, se exigirá a los prestadores de los servicios turísticos de intermediación, de organización de actividades de turismo activo y de alojamiento en campamentos de turismo, como requisito para el ejercicio de la actividad y con carácter previo a la inscripción en el Registro de Turismo de Andalucía, la suscripción de un seguro de responsabilidad civil profesional adecuado u otra garantía equivalente que cubra los daños que se puedan provocar en la prestación de dicho servicio turístico, cuyos términos se determinarán reglamentariamente. ${ }^{63}$ Sí recoge clasificación de hasta tres categorías el Decreto valenciano 92/2009, de 13 de julio, que aprueba el reglamento regulador de las viviendas turísticas denominadas apartamentos, villas, chalets, bungalows y similares, y de las empresas gestoras, personas jurídicas o físicas, dedicadas a la cesión de su uso y disfrute en el ámbito territorial de esta Comunidad.

${ }^{64}$ La suficiencia de la información que el usuario recibe a través de estos portales se destaca en alguna norma autonómica: tal es el caso de Castilla y León, donde la no clasificación de estas viviendas en categorías se justifica, precisamente, en la información suficiente que los usuarios reciben; de manera que en el Preámbulo del Decreto 3/2017, de 2017, de 16 de febrero, que regula los establecimientos de alojamiento en la modalidad de vivienda de uso turístico en dicha Comunidad puede leerse que: «De acuerdo con las características de este tipo de establecimientos de alojamiento turísticos la exigencia de requisitos técnicos es mínima y básica. En este sentido no se establecen categorías que sirvan de referencia para informarse sobre la calidad de los establecimientos ya que el turista tiene información suficiente a través de medios tecnológicos para conocer las características de las viviendas de uso turístico».
} 
concepto de señal que se entenderá a cuenta del importe de los servicios reservados y hasta un máximo del $30 \%$ del total.

\section{RÉGIMEN SANCIONADOR}

Como es sabido, uno de los principales problemas que presenta la supresión del régimen de la previa autorización administrativa de las actividades turísticas es el relativo a la eficacia de los sistemas de control a posteriori de estas actividades privadas. Así, pues, el éxito del régimen instaurado por el DVFT depende de la eficacia de la actividad de los servicios de inspección y del ejercicio debido de la potestad sancionadora, imponiendo, además, las sanciones suficientemente disuasorias.

En Andalucía el desempeño de la actividad inspectora se encomienda a la Consejería competente en materia de turismo «sin perjuicio de las competencias de inspección y control que tengan atribuidas otras Consejerías o Administraciones Públicas», referencia esta última que debe entenderse como un expreso reconocimiento del papel principal que en esta materia tienen los Ayuntamientos.

Además, como ocurre en cualquier ámbito de la actividad administrativa, el adecuado desarrollo de las funciones de inspección requiere la necesaria colaboración del sujeto que desarrolla la actividad ${ }^{65}$, colaboración que el DVFT refiere al propietario del servicio, que el DVFT presume como explotador, salvo que se deje constancia de que dicha explotación se realiza por persona distinta. En este caso responderán ambos sujetos de la correcta prestación del servicio ante la Administración pública; y en el supuesto de que sea el propietario quien asume la explotación, será éste el responsable.

Y no deben olvidarse los principales problemas que se plantean en relación con el ejercicio de la actividad inspectora mediante el acceso a las viviendas. Así, para eludir la actividad inspectora no cabe alegar -como se precisa en alguna norma autonómica- la condición de domicilio, aunque plantea dudas cuando se trata de la cesión del uso de habitaciones.

En cuanto a las previsiones sancionadoras, el DVFT no concreta o especifica las infracciones posibles ni las sanciones correspondientes, remitiéndose, como el resto de las CCAA, a lo dispuesto en su homóloga Ley de Turismo (Título VIII), que clasifica unas y otras en leves, graves y muy graves ${ }^{66}$.

\section{BIBLIOGRAFÍA}

CEBALlOS MARTÍN, Ma M. y PÉREZ GUERRA, R., «A vueltas con el régimen jurídico-administrativo de la distribución de competencias en materia de turismo y de otros títulos que pueden que inciden directamente sobre el mismo: el

\footnotetext{
${ }^{65}$ Deber de colaboración que consagra el artículo 66 de la LTA al prever que: «Las personas titulares de las empresas y actividades turísticas, sus representantes legales o, en su defecto, personas debidamente autorizadas están obligados a facilitar al personal funcionario de los servicios de inspección, en el ejercicio de sus funciones, el acceso a las dependencias e instalaciones y el examen de documentos, libros y registros directamente relacionados con la actividad turística, así como a facilitar la obtención de copias o reproducciones de la documentación anterior.

${ }^{66}$ Arts. 69 y ss. LTA.
} 
ejercicio de competencias turísticas por la Comunidad Autónoma andaluza», RAAP núm. 27 (1996) págs. 95-170.

COMISIÓN NACIONAL DE LOS MERCADOS Y DE LA COMPETENCIA, Informe económico sobre el Decreto 113/2015, de 22 de mayo, por el que se aprueba el Reglamento de las viviendas vacacionales de la Comunidad Autónoma de CanariasLA/03/15, disponible a texto completo en https://www.cnmc.es/file/106805/download

DE LA ENCARNACIÓN, A. M ${ }^{\mathrm{a}}$, «El alojamiento colaborativo: viviendas de uso turístico y plataformas virtuales», REALA núm. 5 (enero-junio 2016), disponible a texto completo en: http://revistasonline.inap.es/index.php?journal=REALA\&page $=$ article \&op=view\&path $\% 5 \mathrm{~B} \% 5 \mathrm{D}=10350 \&$ path\%5B $\% 5 \mathrm{D}=10927$

GOSÁLVEZ PEQUEÑO, H., «El derecho del turista a reclamar: las "hojas de quejas y reclamaciones" en la legislación española, en especial en la legislación de defensa de los consumidores de Andalucía y en la normativa turística de Galicia y de Baleares», International Journal of Scientific Management and Tourism, Vol. 2 núm. 4 (2016,) págs. 51-68

GUILLÉN NAVARRO, N.A., «La vivienda de uso turístico y su incidencia en el panorama normativo español», RArAP núm. 45-46 (2015), págs. 101-144.

LEIÑENA MENDIZÁBAL, E., «Los nuevos sistemas de utilización compartida de vehículos de transporte (carpooling» $\mathrm{y}$ «car sharing»): entre la economía colaborativa y la competencia desleal», Revista de Derecho mercantil núm. 296 (2015), págs. 283334.

MARTOS CALABRÚS, M ${ }^{\mathrm{a}}$ A., «El contrato de arrendamiento de vivienda vacacional tras la reforma del artículo 5 de la LAU por la Ley 4/2013», Revista de Derecho Civil vol. I, núm. 1 (enero-marzo 2014), pág. 91-102.

PÉREZ GUERRA, R., «La regulación jurídico-administrativa de la intermediación turística en España a la luz de la nueva Directiva de Viajes Combinados», RArAP núm. 49-50 (2017), págs. 422-453.

PÉREZ GUERRA, R., «La intervención administrativa en el sector turístico español: la política turística», RArAP núm. 43-44 (2011), págs. 396-423.

ROCA FERNÁNDEZ-CASTANYS, $\mathrm{M}^{\mathrm{a}}$ L., «Régimen jurídico-administrativo del derecho de admisión en establecimientos públicos. Especial referencia al caso andaluz”, RArAP núm. 36 (2010), págs. 313-358.

ROMÁN MÁRQUEZ, A., «Las viviendas particulares dedicadas a la actividad de alojamiento turístico. Su exclusión de la Ley de arrendamientos urbanos», RIDJ vol.6 (2014), disponible en https://w3.ual.es/revistas/RevistaInternacionaldeDoctrinayJurisprudencia/pdfs/201406/articulos_viviendas-particulares.pdf

VERDERA IZQUIERDO, B., «El arrendamiento de temporada frente a las estancias turísticas en viviendas», El consultor inmobiliario núm. 107 (2009), ref. La Ley 20298/2009. 